\title{
EVASÃO ESCOLAR E ENSINO MÉDIO: UMA REVISÃO BIBLIOMÉTRICA
}

\author{
Cristiana Barcelos da Silva ${ }^{1}$ \\ Universidade do Estado de Minas Gerais
}

\begin{abstract}
Resumo
A presente pesquisa trata do tema Evasão Escolar que parece relevante no contexto da educação, pois, produz significativos impactos no interior dos sistemas e instituições de ensino. Demonstrando também de grande importância na trajetória de vida dos estudantes e na elaboração de políticas públicas educacionais. Objetiva apresentar um mapeamento organizado das principais categorias de análises relacionadas com a Evasão Escolar no Ensino Médio. Pautou-se em uma revisão bibliográfica sistemática associadas ao fenômeno em estudo. Nela, descreveu-se as características das investigações que relacionavam Evasão Escolar e Ensino Médio indexados na base de dados Scopus Elsevier, entre os anos de 2014 e 2018. Enquanto resultado, verificou-se que a maior parte das investigações encontradas na base analisada foram pesquisas descritivas que apresentavam um "retrato detalhado" do problema educacional. Em menor proporção, apareceram as investigações que propuseram ações práticas para a redução da Evasão Escolar no Ensino Médio, no contexto escolar.
\end{abstract}

Palavras-chave: Evasão Escolar, Ensino Médio, Bibliometria.

\section{School evasion and High School: a bibliometric review}

\section{Abstract}

This research deals with the topic School Evasion, which seems relevant in the context of education, since it produces significant impacts within the systems and educational institutions. It also demonstrates great importance in the students' life trajectory and in the elaboration of public educational policies. It aims to present an organized mapping of the main categories of analysis related to School Dropout in High School. It was based on a systematic bibliographic review associated with the phenomenon under study. It described the characteristics of the investigations that related School Dropout and High School indexed in the Scopus Elsevier database, between the years 2014 and 2018. As a result, it was found that most of the investigations found in the analyzed base were descriptive researches that presented a "detailed portrait" of the educational problem. To a lesser extent, there were investigations that proposed practical actions to reduce school dropout in high school, in the school context.

Keywords: School Dropout, High School, Bibliometry.

\section{Evasión Escolar y Escuela Secundaria: una revisión bibliométrica}

\section{Resumen}

Esta investigación aborda el tema Evasión escolar, que parece relevante en el contexto de la educación, ya que produce impactos significativos dentro de los sistemas e instituciones educativas. También demuestra gran importancia en la trayectoria de vida de los estudiantes y en la elaboración de políticas públicas educativas. Tiene como objetivo presentar un mapeo organizado de las principales categorías de análisis relacionadas con la deserción escolar en la escuela secundaria. Se basó en una revisión bibliográfica sistemática asociada al fenómeno en estudio. Describió las características de las investigaciones que relacionan el abandono escolar y el bachillerato indexadas en la base de datos Scopus Elsevier, entre los años 2014 y 2018 . Como resultado, se encontró que la mayoría de las investigaciones encontradas en la base analizada fueron investigaciones descriptivas que presentaron un "retrato detallado" del problema educativo. En menor medida, hubo investigaciones que propusieron acciones prácticas para reducir la deserción escolar en el bachillerato, en el contexto escolar.

Palabras clave: Abandono de escuela, Escuela secundaria, Bibliometría

\section{INTRODUÇÃO}

A presente pesquisa busca descrever os passos utilizados para a elaboração da pesquisa bibliométrica. Tomando a Evasão Escolar no Ensino Médio (EM) como foco de análise procurou-se, a partir do reconhecimento da temática compreender a diversidade de interpretações inerentes a ela. Aventurou-se por uma averiguação das investigações que versavam sobre a Evasão Escolar no

\footnotetext{
${ }^{1}$ Pós-doutora em Cognição e Linguagem pela Universidade Estadual do Norte Fluminense Darcy Ribeiro (UENF-Brasil) com estágio de doutoramento no exterior na Faculdade de Ciências Sociais e Humanas (FCSH) da Universidade Nova de Lisboa (UNL-Portugal). Professora na Universidade do Estado de Minas Gerais (UEMG), MG, Brasil. ORCID: https://orcid.org/0000-0003-2196-467X. E-mail: cristianabarcelos@gmail.com
} 
Pil I Cristiana Barcelos da Silva

EM divulgadas em uma base de dados. A intenção da descrição é detalhar as etapas percorridas na fase de planejamento da revisão que consistiram, desde a identificação do tipo e escolha da base de dados mais apropriada a ser explorada e a definição das estratégias de busca disponíveis na base escolhida. Por fim, apresenta-se o número de trabalhos extraídos e algumas descobertas referentes a apreciação e análise da revisão bibliométrica.

\section{RASTRO INVESTIGATIVO}

Como de práxis nas investigações pautadas na construção de Revisão Sistemática e Bibliométrica, do ponto de vista metodológico, busca-se definir um protocolo investigativo. Determina-se normas, regras e parâmetros de configuração para as buscas e, portanto, construção da pesquisa. Faz parte desse momento, a definição da estratégia de busca, a escolha da base de dados; o planejamento para a organização documental; a caracterização, padronização, seleção dos artigos e disposição de portfólio bibliográfico (CORDEIRO; OLIVEIRA; RENTERIA, 2007).

A opção pela base de dados Scopus Elsevier se deu por ser considerada a maior em termo de banco de dados de resumos e citações, de literatura revisada por pares que indexa revistas científicas, livros e trabalhos de conferência (Dantas, 2004). A base oferece a visão mais abrangente sobre a produção de pesquisa do mundo nas áreas de Ciência, Tecnologia, Medicina, Ciências Sociais, Artes e Humanidades. Inclui desde o ano 2015, mais de 50 milhões de registros, 21.000 títulos e 5.000 editores em que tinham acesso restrito, ou acesso apenas ao resumo ou mediante assinatura (ELSEVIER, 2017).

Na visão de Rocha (2015), outra característica da Scopus Elsevier seria o fato de possuir uma cobertura geográfica global, garantindo uma representação mais eficiente da produção científica atual, principalmente dos países emergentes como China, Índia e Brasil mesmo sendo cerca de $60 \%$ das publicações, de origem europeia.

Ainda nesta fase, definiu-se como estratégia de busca (CONFORTO; AMARAL; SILVA, 2011) do operador lógico "or", a fim de abarcar todos os documentos que continham qualquer uma das palavras definas. Como operador racional, optou-se pelas aspas ("')) de modo a sinalizar para a especificação dos termos utilizados. Como definição protocolar, outras delimitações necessárias seriam aos filtros, como o tipo de documento. Nesse caso, uma delas foi a escolha por artigo e artigo de revisão. Pela necessidade de apontar para a atualização da investigação os idiomas escolhidos foram todos.

Do ponto de vista prático, no primeiro momento, a fim de compreender as características das bases de dados disponíveis, acessou-se o Portal de Periódico da Coordenação de Aperfeiçoamento de Pessoal de Nível Superior (CAPES) institucional destinada a Comunidade Acadêmica Federada (CAFE) para escolher a base mais adequada para a presente investigação, como foi possível visualizar na figura 1 : 
[i] | Evasão escolar e ensino médio: uma revisão bibliométrica

Figura 1 - Print da tela inicial do site de periódicos CAPES para instituições.

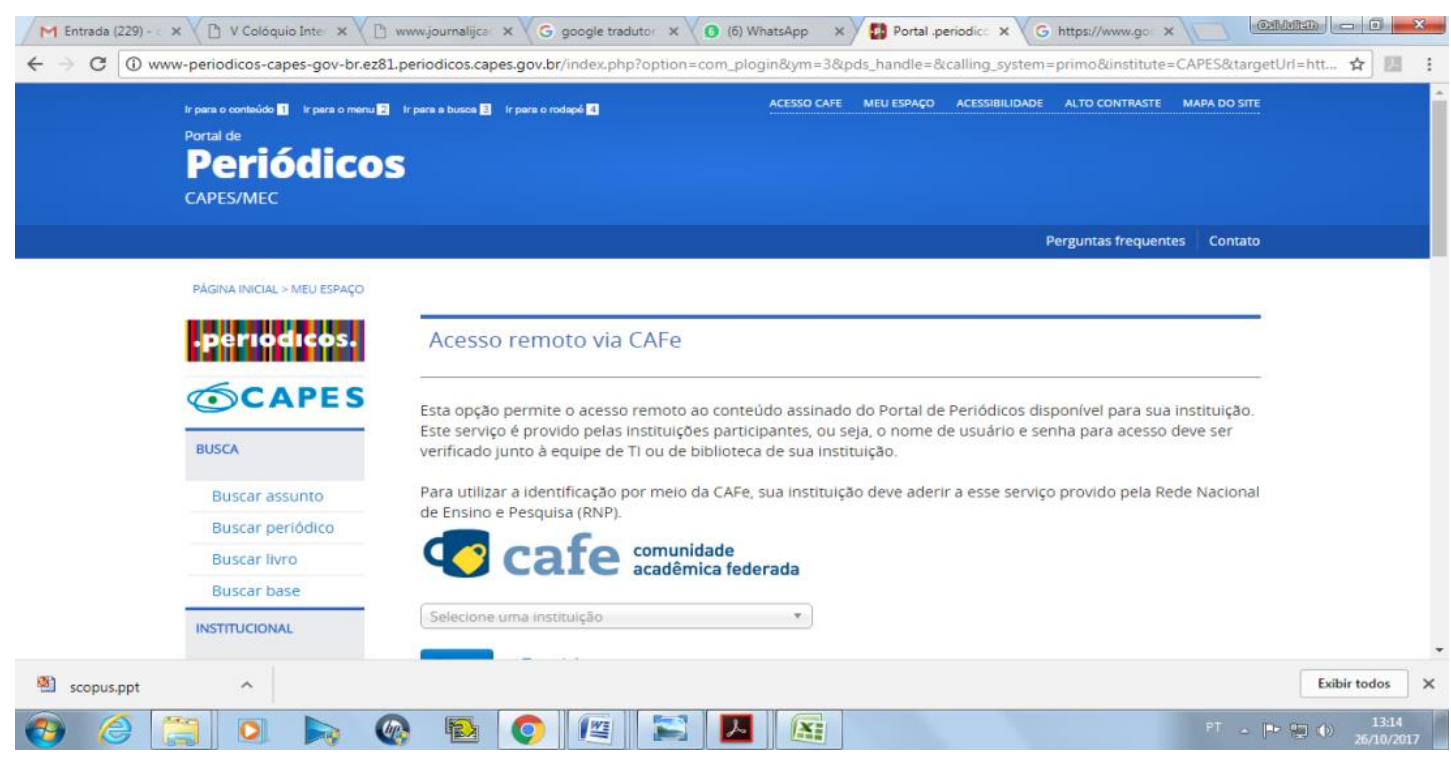

Fonte: Scopus Elsevier (2018).

Percebe-se que pela natureza federada, somente as instituições que comporiam a Rede Nacional de Ensino e Pesquisa (RNEP) previamente cadastradas poderiam ter acesso as bases disponíveis para as instituições. O caminho para o acesso se daria após seleção no campo "instituição" e identificação pessoal. Por conta de uma parceria com uma pesquisadora da UENF foi possível o acesso, como mostra a figura 2:

Figura 2 - Print da tela inicial de acesso o site de periódicos CAPES para instituições cadastradas

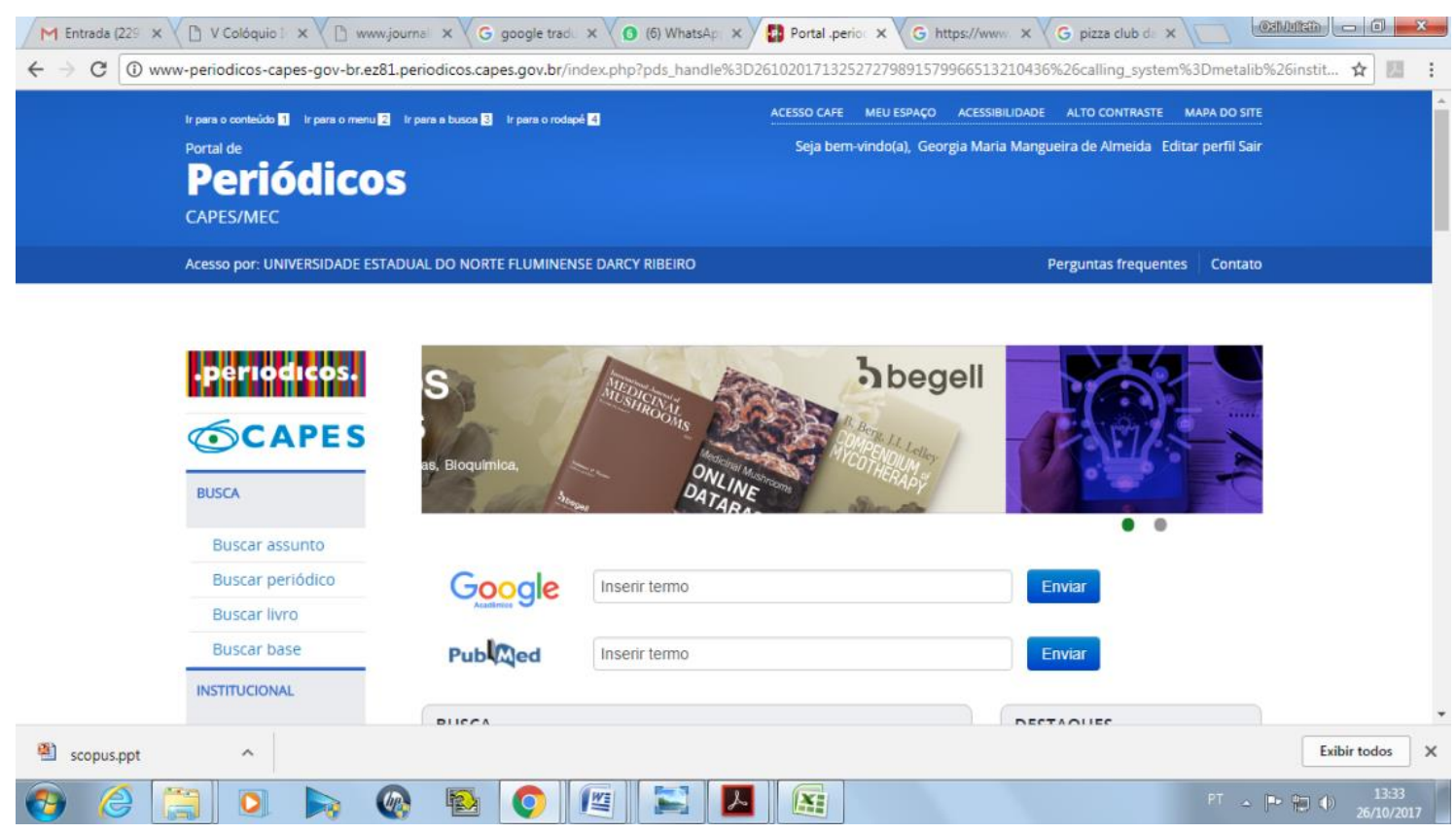

Fonte: Scopus Elsevier (2018).

Em seguida, explorou-se ainda na página de periódicos, a opção de escolha da base de dados. Escolhemos a Scopus Elsevier por ter seus trabalhos indexados, apresentarem a versão final das pesquisas (diferente de outras bases que apresentam a chamada literatura cinzenta que disponibilizam artigos em prelo, aceitos e ainda não publicados e em desenvolvimento) e, 
ifil | Cristiana Barcelos da Silva

sobretudo, por ser interdisciplinar (oferecendo a possibilidade de verificar artigos publicados em periódicos de diferentes áreas do conhecimento), conforme elucidam Ferenhof e Fernandes (2016). Escolhida a base, a página que apareceu foi a da figura 3:

Figura 3 - Print da página inicial da base Scopus Elsevier

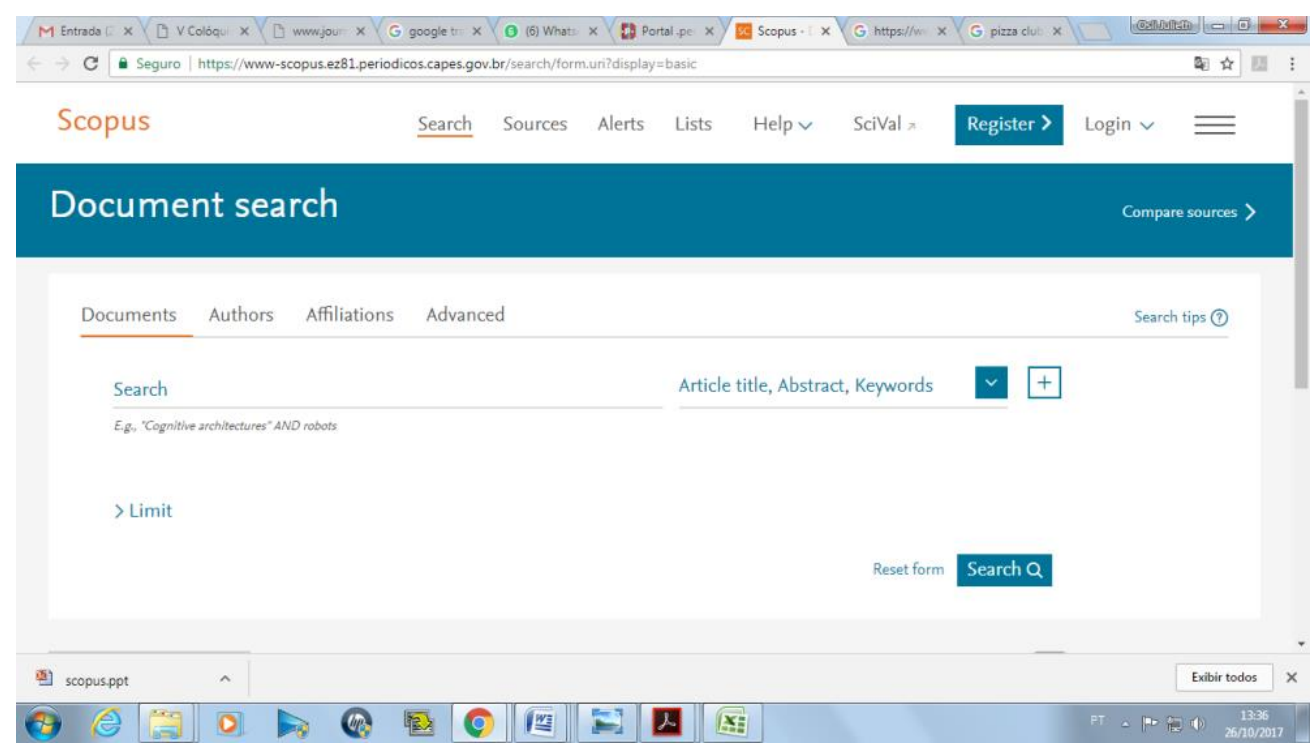

Fonte: Scopus Elsevier (2018).

A opção pela base de dados Scopus Elsevier também se deu por ser considerada a maior em termo de banco de dados de resumos e citações, de literatura revisada por pares que indexa revistas científicas, livros e trabalhos de conferência. Importante ressaltar que se tratando de base de dados, indexação significa o processo seguido por pesquisadores e instituições para dar visibilidade aos artigos publicados, para divulgação e disseminação internacional da produção científica, além de manter seu registro (preservando sua memória), facilitando assim a sua verificação por meio de indicadores específicos de produção científica (DANTAS, 2004).

Uma tentativa realizada em 12 de julho de 2018 as 16:11h quando estabeleceu-se como estratégia de busca 4 expressões ou query string ("corda de consulta" ou, tentando uma tradução para o português brasileiro seria palavras-chave), a saber: i) "drop out high school", ii) "dropping out high school", iii) "high school evasion" e iv) "high school dropout". Foram utilizadas por serem compreendidas como termos que nos levariam a encontrar publicações que abordasse a Evasão Escolar no Ensino Médio. Utilizou-se as aspas para marcar as sentenças e operador lógico OR como recurso de busca. A princípio, a base gerou 669 publicações, como mostra a figura 4: 
Figura 4 - resultado preliminar de buscas de documentos na Scopus Elsevier sobre evasão no ensino médio em 12/07/2018

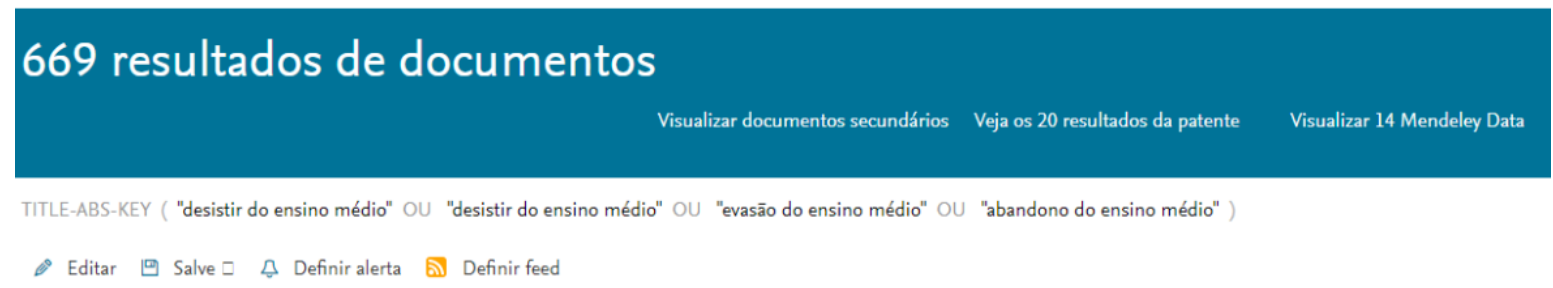

Fonte: Scopus Elsevier (2018).

Dando prosseguimento a pesquisa, estabeleceram-se outros critérios de buscas e tomaram-se algumas decisões metodológicas conforme (BOTELHO, CUNHA E MACEDO, 2011). A primeira delas foi estabelecer alguns refinamentos de busca dos resultados: i) por ano (de modo a verificar as publicações mais recentes, a saber, últimos 5 anos, de 2014 a 2018); ii) por áreas de conhecimento mais próximas da educação (Ciências Sociais e Artes e Humanidades); e iii) por tipo de documento mais adequado para a pesquisa em questão (artigo e artigo de revisão). Feito os devidos refinamentos encontrou-se por fim, no dia 02/10/2017 um total de 81 trabalhos, como pode ser visualizado na figura 5:

Figura 5 - resultado final de buscas dos documentos na Scopus Elsevier em 12/07/2018

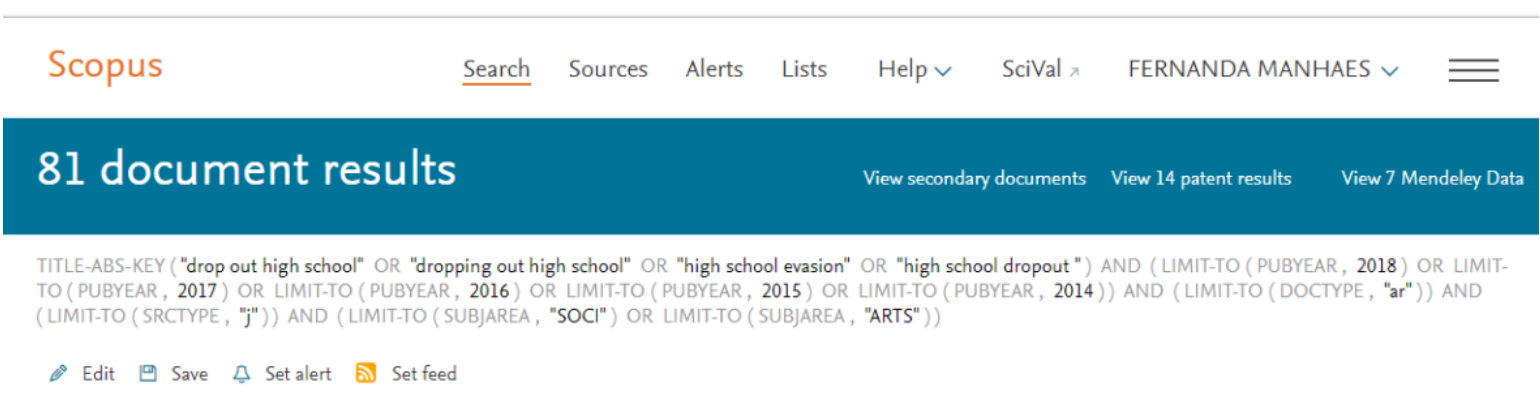

Fonte: Scopus Elsevier (2018).

A priore analisou-se superficialmente os títulos de cada artigo, assim como alguns dados estatísticos provenientes da busca. A partir destas, foi possível verificar que mesmo não considerando todo o ano de 2018, o mais expressivo quanto às publicações sobre Evasão Escolar no Ensino Médio foi o de 2014, como mostram os gráficos 1 e 2: 
Gráfico 1 - Quantidade de artigos por ano (de 2014 ao primeiro semestre de 2018).

\begin{tabular}{lr} 
Year $\downarrow$ & Documents $\uparrow$ \\
\hline 2018 & 13 \\
\hline 2017 & 13 \\
\hline 2016 & 15 \\
\hline 2015 & 18 \\
2014 & 22
\end{tabular}

Fonte: Scopus Elsevier (2018).

Os gráficos demonstram um decréscimo numérico de trabalhos indexados na base com a temática em questão. Levando em consideração os últimos 5 anos e a proporção entre o ano de maior quantidade de trabalhos publicados (2014) e o de menor (2017) foi possível inferir que o decréscimo foi de aproximadamente $59 \%$.

Ainda explorando os dados quantitativos de busca, quanto aos lugares de origem das pesquisas, foi possível descobrir no período analisado a "geografia" das pesquisas sobre Evasão Escolar no Ensino Médio, conforme o gráfico a seguir:

Gráfico 2 - Publicação dos artigos por cidade/território

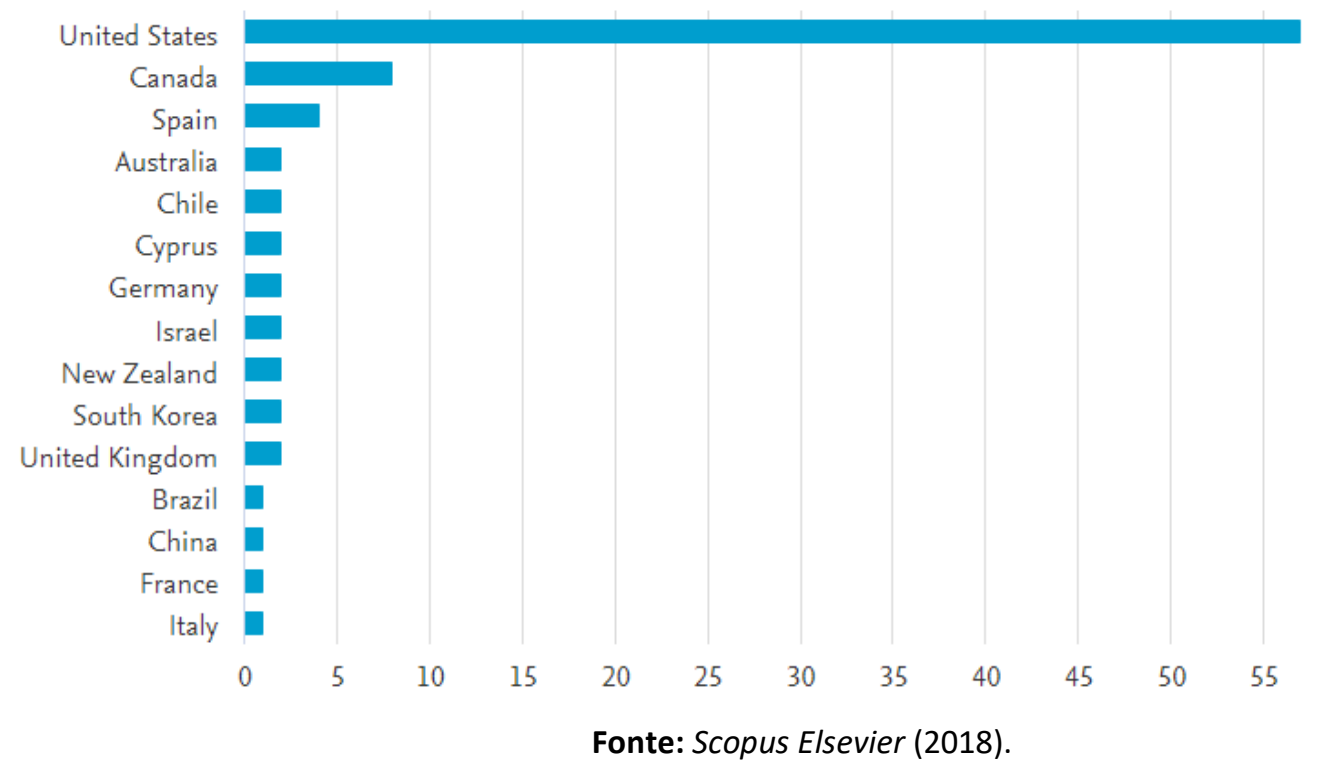

Além de evidenciar os Estados Unidos da América com um maior número de trabalhos de pesquisa indexados na base de dados, como constatou Gomes (2018) ao tratar da Evasão no 
ilil | Evasão escolar e ensino médio: uma revisão bibliométrica

Ensino Superior, importa ressaltar que mesmo não aparecendo no gráfico os países México, Holanda, Paquistão, Taiwan e Peru se juntam aos últimos da lista com 1 publicação no período pesquisado.

Explorando os trabalhados encontrados, percebeu-se que seria possível traduzir os resumos na própria base de dados, clicando no botão esquerdo do mouse e escolhendo a opção "traduzir esta página". A opção de certo modo, possibilitaria compreender de forma geral, o assunto tratado. Nesse momento, também verificou-se na opção Refine Results que alguns periódicos não apresentavam publicações por um período de tempo, talvez pelo fato de no período investigado não haver cobertura para indexação do periódico na base de dados consultada, a Scopus Elsevier. Como encontra-se nos escritos de Rocha (2015), para serem indexados em bases de dados os periódicos devem que estar de acordo com todos os critérios de qualidade estabelecidos por elas.

Como era necessário saber se os artigos gerados no resultado tinham relação com a Evasão Escolar no Ensino Médio, posterior à etapa de sistematização das informações quantitativas transportou-se e organizou-se os dados em um software de planilha eletrônica (Excel). Nela, as colunas continham um número do controle (no formato cardinal atribuído pela pesquisadora), comentários sínteses (que descrevia as peculiaridades do artigo), os títulos traduzidos e os resumos traduzidos.

Em posse da planilha com os artigos indexados e divulgados na base de dados, uma das tarefas cumpridas, com o propósito de identificar inicialmente se haveria relação entre a proposta dos artigos com o tema, foi hachurar de vermelho os que não tinham relação e de verde os que estabeleciam relação direta com a temática. Ainda nesta fase, criou-se filtros de seleção, foi feita a leitura dos títulos e dos resumos cada artigo. Realizada a identificação e verificação dos trabalhos que de fato estavam alinhados ao tema de busca verificou-se que do total de 81 trabalhos, 14 não estabeleciam relação direta e, portanto, 67 foi a amostra final total de trabalhos selecionados para a fase de análise descrita a seguir.

\section{MAPEAMENTO E CATEGORIZAÇÃO DOS ESTUDOS SOBRE EVASÃO ESCOLAR NO ENSINO MÉDIO NA BASE DE DADOS SCOPUS ELSEVIER}

Um dos objetivo orientou-se em mapear e organizar as categorias relacionadas com a Evasão Escolar, dentre a produção de conhecimento recente no contexto das investigações publicadas na base de dados Scopus Elsevier. Sua intencionalidade esteve motivada na tentativa de visualizar de forma ampliada os principais aspectos influentes nas produções contemporâneas sobre o tema.

Por isso, após escolha da base de dados, planejamento para a organização dos documentos, a caracterização, padronização e seleção dos artigos, construiu-se um portfólio bibliográfico de artigos com todos os arquivos. O total de trabalhos que constitui o portfólio bibliográfico de artigos indexados na Scopus Elsevier que tratavam da Evasão Escolar no Ensino Médio, como objeto de estudos, foi 67 de trabalhos entre anos de 2014 e 2018.

Diante dos dados coletados e organizados do portfólio, a tarefa seguinte envolveu a leitura dos documentos encontrados, seguido da análise, síntese e escrita dos achados da pesquisa. Inspirando-se em Bardin (2010) os artigos foram classificados, de acordo com sua abordagem em 3 categorias de análises, a saber: I) somente descritivo; II) somente propositivo; e III) parte descritivo e parte propositivo. 


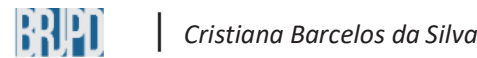 \\ I) Descritivos:}

Seguindo uma tendência histórica que marcam as investigações brasileiras sobre Evasão Escolar que se propuseram a encontrar as causas para o fenômeno, o primeiro grupo, maioria dos trabalhos (aproximadamente 73\%), se caracterizou por apresentar os fatores considerados causadores da Evasão Escolar no Ensino Médio, conforme tabela a seguir:

Tabela 1 - Classificação analítica dos trabalhos sobre Evasão Escolar no Ensino Médio indexados na Scopus Elsiever (2014/2018).

\begin{tabular}{|c|c|}
\hline TIPOLOGIA DA INVESTIGAÇÃO & NÚMERO DE TRABALHOS \\
\hline Descritivos & 49 \\
\hline Propositivos & 7 \\
\hline Descritivos e Propositivos & 11 \\
\hline
\end{tabular}

Fonte: arquivo de pesquisa (2018).

Nos artigos categorizados como descritivos emergiu entre os pesquisadores uma preocupação com a Evasão Escolar enquanto saída precoce do estudante das instituições de ensino que ofertavam o EM (ou similar). Além de serem quase que unânimes ao indicar um único fator como responsável pela evasão dos estudantes (46 artigos), outra questão que chamou a atenção foi o número de artigos que apontaram o indivíduo-estudante (41 artigos) como responsável pela Evasão Escolar no Ensino Médio, seguidos da estrutura social (10 artigos), das instituições educativas ( 12 artigos) e de determinantes familiares (4 artigos). Se tratando dos descritores, os que em síntese surgiram como categorias responsáveis pelo fenômeno educacional foram as seguintes:

Gráfico 3 - Categorias descritivas que nos artigos indexados na Scopus explicaram a causa da Evasão Escolar no Ensino Médio

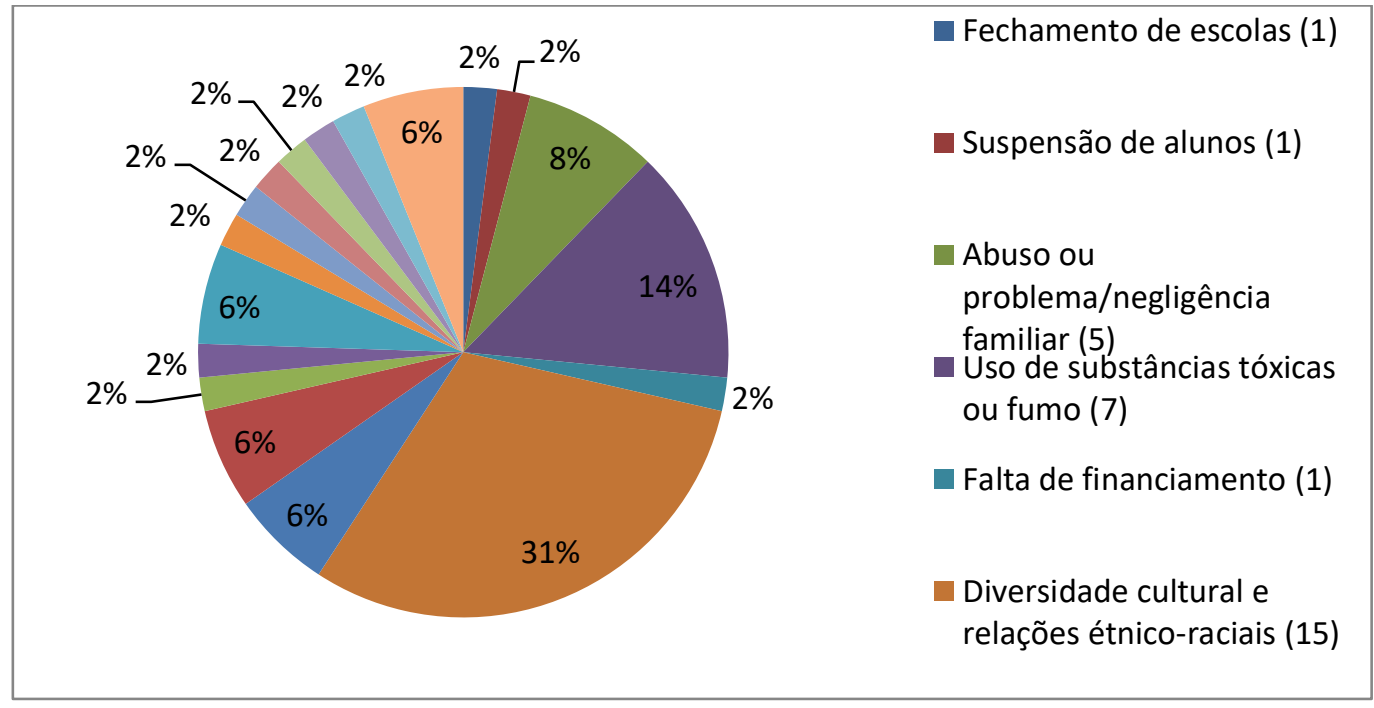

Fonte: arquivo de pesquisa (2018).

Segundo análise dos artigos, a Evasão Escolar nas instituições podem envolver muitas questões. Por esta razão, os estudos buscaram compreender quais os fatores mais influenciavam na evasão como objeto de pesquisa e no presente levantamento, o primeiro fator que em números 
|il Evasão escolar e ensino médio: uma revisão bibliométrica

absolutos ficou mais evidente foi "diversidade cultural e as relações étnico-raciais". Um exemplo de tal constatação pode ser encontrado no artigo de Achambault et al. (2017), quando afirmou que na maioria dos países ocidentais, as características individuais, sociais e familiares estão intimamente associadas à evasão dos estudantes na população em geral.

Pesquisas relatam que outro motivo que pode afastar os estudantes das instituições escolares é o vício. A dependência de substâncias tóxicas e que podem gerar uma dependência psicológica e/ou emocional, às pessoas podem afastá-las dos bancos escolares (GILHOOLY et al., 2008).

O terceiro fator preponderante nas análises foram os que de algum modo estabeleciam relação com a família (SYMEOU, MARTíNEZ-GONZALEZ, E ÁLVAREZ-BLANCO, 2014). Parte das pesquisas que descreviam as razões que levavam à Evasão Escolar dos estudantes no Ensino Médio explicavam que eles o faziam, por questões como algum tipo de abuso ocorrido na família, negligência ou problemas de outras ordens provenientes de suas famílias.

Seguindo na análise bibliométrica, os fatores que apareceram quarto lugar foram múltiplos. Dentre eles estavam: distúrbios psicológicos (FERGUSSON, MCLEOD; HORWOOD, 2015), fatores institucionais (JIA, KONOLD E CORNELL, 2016) e a questão da gravidez/maternidade na adolescência (BERG; NELSON, 2016; AUGUSTINE, 2016).

Do ponto de vista numérico, outros princípios que surgiram (em menor quantidade na amostra) como impactantes na Evasão Escolar no Ensino Médio dos alunos foram: fechamento de escolas, suspensão de alunos, falta de financiamento, violência urbana, escassez de pesquisas na área e questões relativas ao conceito de evasão.

Diante da amostra de artigos, apareceram com relevâncias similares os elementos referentes às questões de ordem extraescolar (fatores referentes a questões não institucionais) e intraescolares (questões ligadas às instituições educacionais).

Percebeu-se que as dimensões conceituais prevalentes nas pesquisas sobre Evasão Escolar no Ensino Médio, indexadas na base de dados Scopus Elsiever, focaram nas razões que motivaram a evasão, cuja perspectiva quanto ao recorte dado à investigação, teve como ponto de partida o indivíduo e de maneira muito tímida, o papel das instituições escolares e das ações que poderiam ser desenvolvidas no interior delas, para diminuir os indicadores de evasão entre os estudantes.

Foi também possível identificar as três perspectivas de análises abordadas nos modelos teóricos de Evasão Escolar, a saber: a Individual, a Institucional e o Contexto Social. Contudo, elas não se apresentaram, do ponto de vista quantitativo, de maneira equilibrada. Sua distribuição ficou definida da seguinte maneira:

Gráfico 4 - Perspectiva de análise das investigações publicadas na base de dados Scopus Elsevier (2014-2018) 


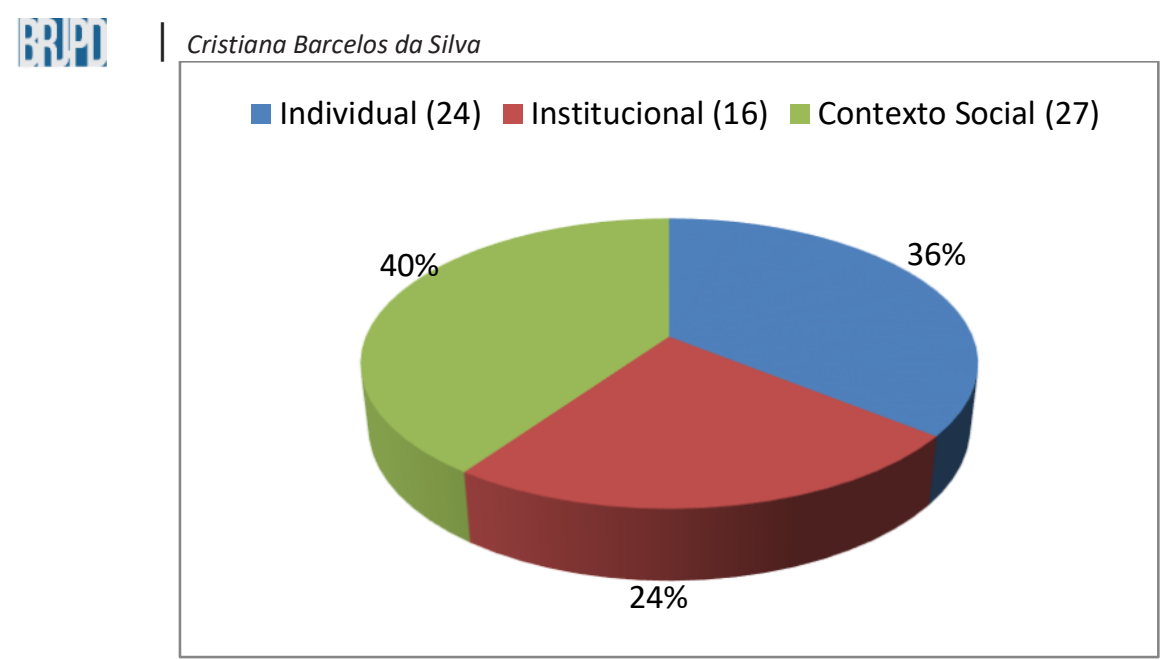

Fonte: dados da pesquisa (2019).

O primeiro bloco expõe a dimensão do Contexto Social que envolve as condições contextuais envolvidas no processo de Evasão Escolar, sobretudo as levando em consideração os níveis socioambientais que extrapolam o espaço físico das instituições escolares. Questões como Escolarização Prévia, Suporte Familiar e Condições Financeiras são profundamente analisadas como determinantes no processo de Evasão Escolar, fundamentados nos estudos de Cabrera, Nora e Castañeda (1993), Tinto (1983, 1997), e Pascarella (1980).

O segundo, diz respeito à dimensão da pessoa-estudante. Se refere aos aspectos individuais que envolvem os traços pessoais, as competências e habilidades, a auto percepção, a personalidade e a expectativa dos estudantes. Neste levantamento, pode-se concluir que, se tratando das pesquisas recentes indexadas na base de dados Scopus Elsevier, há uma predominância quanto ao papel do objetivo de pesquisa descrição como elemento investigativo e o olhar da Evasão Escolar sob a égide do indivíduo, como considerava Pascarela (1980), Bean e Metzner (1985) Bean e Eaton, (2011).

O terceiro bloco apresenta a dimensão institucional. As investigações que se orientam por essa vertente elegem os aspectos que envolvem um conjunto de processos associados ao protagonismo das instituições escolares em conjunto com o estudante. Mesmo no universo de análise, se apresentando em um menor percentual, quanto à finalidade das pesquisas podem ser classificadas como estratégicas ou aplicadas. Em geral, tratam da Integração Acadêmica, Integração Social, Envolvimento, Feedbak Acadêmico e Orientação Vocacional conforme modelos teóricos de Tinto (1975) e Cabrera et al. (1993;1992).

Tendo em vista o objetivo de mapear e organizar a produção do conhecimento dos estudos que versam sobre a Evasão Escolar no Ensino Médio nos últimos cinco anos identificou-se que a maior parte das investigações encontradas na base de dados Scopus Elsiever foram pesquisas de caráter descritivo, apresentando um "retrato detalhado" do problema. Em menor proporção, apareceram as pesquisas indexadas na base de dados consultada que propuseram ações práticas para a redução do fenômeno da Evasão Escolar no Ensino Médio.

\section{REFERÊNCIAS}

ARCHAMBAULT, Isabell;. JANOSZ, Michel; DUPÉRÉ, Véronique; BRAULT, Marie-Christine; ANDREW, Marie Mc. Individual, social, and family factors associated with high school dropout 
Ii] Evasão escolar e ensino médio: uma revisão bibliométrica

among low-SES youth: Differential effects as a function of immigrant status. British Journal of Educational Psychology, v. 87, n. 3, p. 456-477, 2017.

BEAN, John; EATON, Shevawn. The psychology underlying successful retention practices. Journal College of Student Retention, v.3, n.1, p. 73-89, 2001.

BEAN, John; METZNER, B.S. A Conceptual Model of Nontraditional Undergraduate Student Attrition. Review of Educational Research, v. 55, n. 3, p. 485-540, 1985.

BERG, Nathan; NELSON, Teresa. Pregnancy and dropout: Effects of family, neighborhood, and high school characteristics on girls' fertility and dropout status. Population Research and Policy Review, v. 35, n. 6, p. 757-789, 2016.

BOTELHO, Louise Lira Roedel; C CUNHA, Cristiano Castro de Almeida; · MACEDO, Marcelo. O método da revisão integrativa nos estudos organizacionais. Gestão e Sociedade. Belo Horizonte, v.5, n. 11, p. 121-136 - maio-ago. 2011 - ISSN 1980-5756. Disponível em: <http://www. gestaoesociedade.org/gestaoesociedade/article/view /1220/906>. Acesso em: 27 set. 2018.

CABRERA, Alberto; CASTAÑEDA, Maria. NORA, Amaury; HENGSTLER Dennis. The convergence between two theories of college persistence. The journal of higher education, v. 63, n. 2, p. 143-164, 1992. [Tradução livre por Cristiana Barcelos da Silva].

CONFORTO, Edivandro Carlos; AMARAL, Daniel Capaldo; SILVA, SL DA. Roteiro para revisão bibliográfica sistemática: aplicação no desenvolvimento de produtos e gerenciamento de projetos. In: Anais do $8^{\circ}$ Congresso Brasileiro de Gestão de Desenvolvimento de Produto. Anais do 8o CBGDP, 2011.

CORDEIRO, Alexander Magno; OLIVEIRA, Glória Maria de; RENTERIA, Juan Miguel. Revisão sistemática: uma revisão narrativa. Rev. Col. Bras. Cir, v. 34, n. 6, p. 428-431, 2007.

DANTAS, Paulo Elias C.. Indexação bibliográfica em bases de dados: $O$ que é? Para que serve? Onde estamos?. Arq. Bras. Oftalmol., São Paulo, v. 67, n. 4, p. 569-570, Aug. 2004. Disponível em: <http://www.scielo.br/scielo.php? script=sci arttext \&pid =S0004 $27492004000400001 \& \operatorname{lng}=e n \& n r m=i s o>$. Accesso em: 26 out. 2017.

ELSEVIER. Scopus: Missão em 2017 a. Disponível em: <https://www.elsevier.com/solutions/scopus>. Acesso em: 26.out.2018.

FERGUSSON, David.; MCLEOD, Geraldine ; HORWOOD, John. Leaving school without qualifications and mental health problems to age 30 . Social psychiatry and psychiatric epidemiology, v. 50, n. 3, p. 469-478, 2015.

FERENHOF, Helio Aisenberg; FERNANDES, Roberto Fabiano. Desmistificando a revisão de literatura como base para redação científica: método SFF. Revista ACB, v. 21, n. 3, p. 550-563, 2016.

GILHOOLY, Tara; BERGMAN, Andrea; STIEBER, Joshua; BROWN, Elissa. PosttraumaticStress Disorder Symptoms, Family Environment, and Substance Abuse Symptoms in Emerging Adults. Journal of Child \& Adolescent Substance Abuse, v. 27, n. 3, p. 196-209, 2018.

GOMES. André Raeli. A Evasão Universitária: Um Protótipo Dinâmico de Gestão da Permanência para Instituição de Ensino Superior Privada. 2018, 178p. Tese (Doutorado em Cognição e Linguagem) - Universidade Estadual do Norte Fluminense Darcy Ribeiro, Centro de Ciências do Homem, Campos dos Goytacazes, RJ, 2018.

JIA, Yuane; KONOLD, Timothy R.; CORNELL, Dewey. Authoritative school climate and high school dropout rates. School Psychology Quarterly, v. 31, n. 2, p. 289, 2016.

PASCARELLA, Ernest; How college affects students: Findings and Insights from twenty Years of research. San Francisco: Jossey-Bass Inc, 1980.

ROCHA, Mônica Andrea Brogliatti. Recursos Educacionais Abertos: Publicações Ibero Americanas indexadas na Redalyc, Scopus e Web of Science. Trabalho de Conclusão de Curso (graduação) - Universidade Federal de Santa Catarina, Centro de Ciências da Educação. Graduação em Biblioteconomia. Florianópolis, Santa Catarina, 70 p., 2015. 
Pil | Cristiana Barcelos da Silva

SYMEOU, Loizos; MARTíNEZ-GONZÁLEZ, Raquel Amaya; ÁLVAREZ-BLANCO, Lucía. Dropping out of high school in Cyprus: do parents and the family matter?. International Journal of Adolescence and Youth, v. 19, n. 1, p. 113-131, 2014.

TINTO, Vincent. Classrooms as Communities: Exploring the Educational Character of Student Persistence. The Journal of Higher Education, vol. 68, n. 6 (Nov. - Dec., 1997), p. 599-623, 1997. Disponível em: http://www.jstor.org/stable/2959965. [Tradução livre por Cristiana Barcelos da Silva].

TINTO, Vincent. Leaving college: Rethinking the causes and cures of student attrition. Chicago: The University of Chicago Press, 1983. [Tradução livre por Cristiana Barcelos da Silva].

TINTO, Vincent. Dropout from higher education: A theoretical synthesis of recent research. Review of Education Research v. 45, n. 1, p. 89-125,1975. Disponível em: <

http://journals.sagepub.com /doi/pdf/10.3102/00346543045001089>. Acesso em: 31 mar. 2017. [Tradução livre por Cristiana Barcelos da Silva].

Submetido em: mai. 2021.

Aprovado em: jun. 2021

Publicado em: jun. 2021 